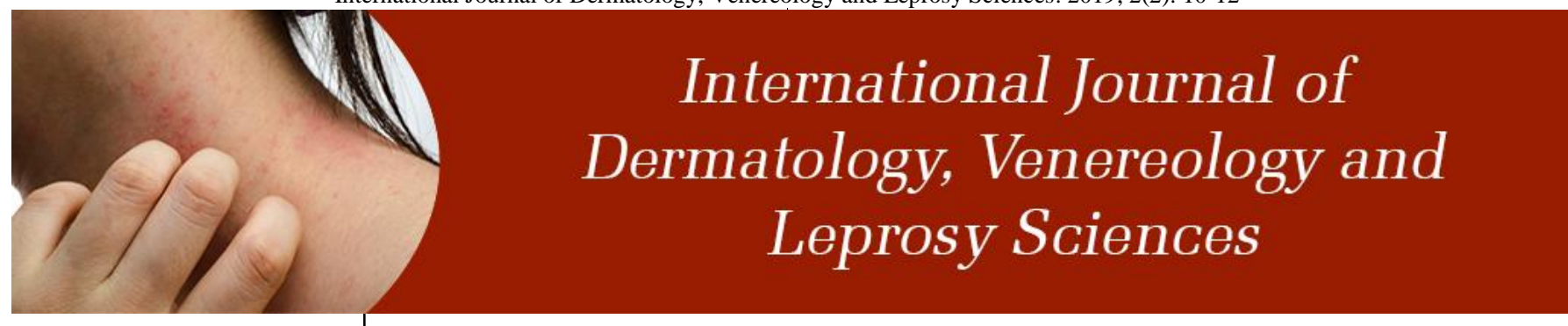

E-ISSN: 2664-942X

P-ISSN: 2664-9411

www.dermatologypaper.com/

Derma 2019; 2(2): 10-12

Received: 10-05-2019

Accepted: 12-06-2019

Dr. Steve Annan

Department of Dermatology,

City College of New York -

Downtown- Center for Worker

Education, New York
Corresponding Author:

Dr. Steve Annan

Department of Dermatology,

City College of New York -

Downtown- Center for Worker

Education, New York

\section{Assessment of thiol level in cases of Non-segmental vitiligo}

\section{Dr. Steve Annan}

DOI: https://doi.org/10.33545/26649411.2019.v2.i2a.25

\begin{abstract}
Introduction: Vitiligo is one of the most prevalent pigmentation disorders in the world characterized by the destruction of melanocytes and the development of white macules and patches on the skin or mucosa. The present study assessed thiol level in cases of Non-segmental vitiligo.

Materials \& Methods: The present study was conducted on 185 cases (Group I) of vitiligo of both genders. Equal number of control (Group II) was also included. Venous blood samples of all participants were collected in tubes containing EDTA after fasting overnight. The total thiol content of the sample was measured using modified Ellman reagent. Values were presented as $\mu \mathrm{mol} / \mathrm{L}$

Results: Out of 185 patients, males were 87 and females were 98 . The mean age of onset of vitiligo was 25.3 years, duration of disease was 21.5 years, VASI score was 0.74 , staging score was 4 and spreading score was 1.2. The mean native thiiol in group I was $485.2 \mu \mathrm{mol} / 1$ and in group II was 450.1 $\mu \mathrm{mol} / 1$, disulphide level was $18.3 \mu \mathrm{mol} / 1$ in group I and $18.7 \mu \mathrm{mol} / 1$ in group II. Total thiol level was $503.5 \mu \mathrm{mol} / 1$ in group I and $468.8 \mu \mathrm{mol} / 1$ in group II. The difference was significant $(P<0.05)$.

Conclusion: Authors found that there was elevated thiol level in patients with vitiligo as compared to control.
\end{abstract}

Keywords: thiol level, Pigmentation, Vitiligo

\section{Introduction}

Vitiligo is one of the most prevalent pigmentation disorders in the world characterized by the destruction of melanocytes and the development of white macules and patches on the skin or mucosa ${ }^{[1]}$. With a global frequency of $0.5 \%-4 \%$, vitiligo occurs in both sexes and all races and ages. Nevertheless, the most common age of onset of the disease is 10-30 years. Vitiligo is known as a condition in which depigmentation of the part of skin occurs. Loss of the functionality of melanocytes is responsible for vitiligo but the real cause of vitiligo is unknown. However, some conditions including autoimmune, genetic, neural, viral infections and oxidatives tress could have an important role in vitiligo ${ }^{[2]}$.

Non-segmental vitiligo (NSV) is a group that comprises acrofacial, mucosal, generalized or common, universal, and mixed forms besides rare forms. Acrofacial form can affect, face, head, hands and feet, and preferably involve the perioral region and the extremities of digits; Mucosal form affects the oral and genital mucosae ${ }^{[3]}$.

Thiols, the organic compounds having sulfhydryl $(\mathrm{SH})$ groups are present as albumin thiols, protein thiols, and less as low molecular weight thiols such as cysteine, cysteinylglycine, glutathione (GSH), homocysteine and gamma glutamylcysteine human plasma. In a dynamic thiol/disulfide homeostasis, these compounds have disulfide bounds under oxidative conditions, which can be reduced to native thiols. Dynamic thiol/disulfide homeostasis regulates the maintenance of antioxidants, detoxification, apoptosis, and many cellular signal mechanisms involving cell division and cell growth ${ }^{[4]}$. The present study assessed thiol level in cases of Non-segmental vitiligo.

\section{Materials \& Methods}

The present study was conducted in the department of Dermatology. It comprised of 185 cases (Group I) of vitiligo of both genders. Equal number of control (Group II) was also included. The study protocol was approved by the Ethics Committee. All were informed regarding the study and written consent was obtained.

Data such as name, age, gender etc was recorded. All patients were subjected to clinical 
scoring according to the Vitiligo Area Scoring Index (VASI) and the extent, stage, and spread of vitiligo of patients were evaluated according to the VETF system.

Venous blood samples of all participants were collected in tubes containing EDTA after fasting overnight. The total thiol content of the sample was measured using modified Ellman reagent. Values were presented as $\mu \mathrm{mol} / \mathrm{L}$. Results thus obtained were subjected to statistical analysis. $\mathrm{P}$ value less than 0.05 was considered significant.

\section{Results}

Table I: Distribution of patients

\begin{tabular}{|c|c|c|}
\hline \multicolumn{3}{|c|}{ Total- 185 } \\
\hline Gender & Male & Female \\
\hline Number & 87 & 98 \\
\hline
\end{tabular}

Table I shows that out of 185 patients, males were 87 and females were 98 .

Table II: Clinical characteristics of vitiligo patients

\begin{tabular}{|c|c|}
\hline Clinical characteristics & Values \\
\hline Age of inset (Years) & 25.3 \\
\hline Duration (Years) & 21.5 \\
\hline VASI score & 0.74 \\
\hline Staging score & 4 \\
\hline Spreading score & 1.2 \\
\hline
\end{tabular}

Table II shows that mean age of onset of vitiligo was 25.3 years, duration of disease was 21.5 years, VASI score was 0.74 , staging score was 4 and spreading score was 1.2 .

Table III: Assessment of thiol level in both groups

\begin{tabular}{|c|c|c|c|}
\hline $\begin{array}{c}\text { Thiol level } \\
(\boldsymbol{\mu m o l} / \mathbf{l})\end{array}$ & $\begin{array}{c}\text { Group I } \\
\text { (Cases) }\end{array}$ & $\begin{array}{c}\text { Group II } \\
\text { (Control) }\end{array}$ & $\begin{array}{c}\text { P } \\
\text { value }\end{array}$ \\
\hline Native thiol & 485.2 & 450.1 & 0.05 \\
\hline Disulphide & 18.3 & 18.7 & 0.92 \\
\hline Total Thiol & 503.5 & 468.8 & 0.01 \\
\hline
\end{tabular}

Table III, graph I shows that mean native thiiol in group I was $485.2 \mu \mathrm{mol} / \mathrm{l}$ and in group II was $450.1 \mu \mathrm{mol} / \mathrm{l}$, disulphide level was $18.3 \mu \mathrm{mol} / \mathrm{l}$ in group I and $18.7 \mu \mathrm{mol} / \mathrm{l}$ in group II. Total thiol level was $503.5 \mu \mathrm{mol} / 1$ in group I and $468.8 \mu \mathrm{mol} / 1$ in group II. The difference was significant $(P<$ $0.05)$.

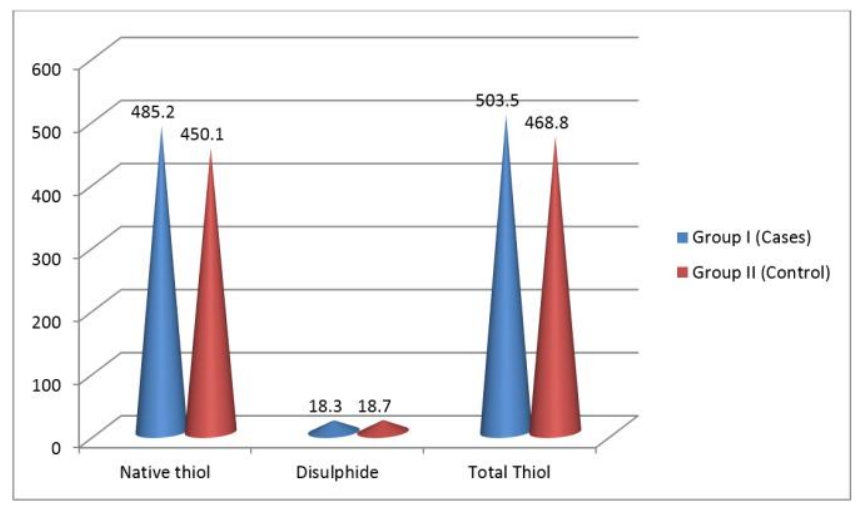

Graph I: Assessment of thiol level in both groups

\section{Discussion}

The most important symptom of vitiligo known is the depigmentation of patches of skin. Initially, the patches are small but they will be enlarged over time. The skin lesions are dominantly observed on the face, hands and wrists. Often patients who are suffering from this disease also suffer from depression ${ }^{[5]}$. The exact pathogenesis of vitiligo is still to be elucidated. The biochemical/cytotoxic hypothesis emphasizes that vitiligo occurs when the melanocyte is killed by cytotoxic precursors to melanin synthesis; the neural hypothesis is based on nerve injury development with effected sites that leads to segmental vitiligo with neurons that interact with melanocytes and release melanocytotoxic substrates the autoimmune hypothesis is based on genetic data which are more associated to autoimmune disease ${ }^{[6]}$. Multiple mechanisms, including metabolic abnormalities, oxidative stress, generation of inflammatory mediators, cell detachment and autoimmune responses, might contribute to the pathogenesis. In particular, the autoimmune mechanism is now clearly established. Vitiligo may appear at any age and affect both sexes. It tends to occur or recur in spring and/or summer ${ }^{[7]}$. The present study assessed thiol level in cases of Non-segmental vitiligo.

In present study, we included 185 patients which males were 87 and females were 98. The mean age of onset of vitiligo was 25.3 years, duration of disease was 21.5 years, VASI score was 0.74 , staging score was 4 and spreading score was 1.2.

Akoglu et al. ${ }^{[8]}$ found that the native and total thiol levels of vitiligo patients were higher than those of healthy control group. The median VASI score of patients was 0.7 . Univariate analyses showed that plasma native thiol levels, VETF spread score, disease duration, and vitiligo type significantly correlated with VASI scores. Stepwise multivariate analysis revealed that disease duration and spread score were found statistically significant as independent factors on VASI score.

We found that mean native thiiol in group I was 485.2 $\mu \mathrm{mol} / 1$ and in group II was $450.1 \mu \mathrm{mol} / 1$, disulphide level was $18.3 \mu \mathrm{mol} / 1$ in group I and $18.7 \mu \mathrm{mol} / 1$ in group II. Total thiol level was $503.5 \mu \mathrm{mol} / 1$ in group I and 468.8 $\mu \mathrm{mol} / \mathrm{l}$ in group II.

Saran $\mathrm{J}^{[9]}$. in their study included 138 patients of vitiligo of both genders. In all subjects, a careful clinical examination was done. Type of vitiligo was evaluated. Out of 138 patients, males were 78 and females were 60. Common type of vitiligo was segmental seen in 36 , nonsegmental in 58 and undetermined in 24.

Our findings pointed to the potential role of excess thiol compounds in vitiligo pathogenesis using possible associated increase of pheomelanogenesis, pheomelanin induced oxidative stress, cell injury, or apoptosis in vitiligo. The clinical picture consists of one or more welldemarcated and white maculae, progressing in size and number. They are asymptomatic generally. The lesions usually appear on sun-exposed or constitutionally hyperpigmented areas or on sites of stretch and pressure (face, dorsum of hands and fingers, external genitalia, knees and elbows). The margins of the patches are often hyperpigmented; hypopigmented areas sometimes occur together with the depigmented lesions and the normally pigmented skin (trichrome vitiligo). Rarely an inflammatory border may be found around the vitiligo patch resulting in a raised and erythematous edge (inflammatory vitiligo). Poliosis circumscripta, as well as canities and premature graying, can be observed; mucosae are rarely involved. Treatment of 
vitiligo includes cosmetic camouflage for the lesions on sun-exposed skin and mandatory prescription of sunscreens in sunny climates ${ }^{[10]}$.

\section{Conclusion}

Authors found that there was elevated thiol level in patients with vitiligo as compared to control.

\section{References}

1. Hamzavi I, Jain H, McLean D, Shapiro J, Zeng H, Lui $\mathrm{H}$ et al. Parametric modeling of narrowband UV-B phototherapy for vitiligo using a novel quantitative tool: The vitiligo area scoring index. Arch Dermatol. 2004; 140:677-83.

2. Jara JR, Aroca P, Solano F, Martinez JH, Lozano JA. The role of sulfhydryl compounds in Mammalian melanogenesis: The effect of cysteine and glutathione upon tyrosinase and the intermediates of the pathway. Biochim Biophys Acta. 1988; 967:296-303.

3. Meyskens FL Jr., Buckmeier JA, McNulty SE, Tohidian NB. Activation of nuclear factor kappa B in human metastatic melanomacells and the effect of oxidative stress. Clin Cancer Res. 1999; 5:1197-202.

4. Singh N, Gera V. Evaluation of Zinc Levels in Patients with Vitiligo- A Clinical Study. J Adv Med Dent Scie Res. 2019; 7(7): 156-158.

5. Patel NS, Paghdal KV, Cohen GF. Advanced treatment modalities for vitiligo. Dermatol Surg. 2012; 38:38191.

6. Butnaru C, Pascu M, Mircea C, Agoroaei L, Solovăstru L, Vâţă D et al. Serum zinc and copper levels in some dermatological diseases. Rev Med Chir Soc Med Nat Iasi 2008; 112:253-7.

7. Das SK, Majumder PP, Chakraborty R, Majumdar TK, Haldar B. Studies on vitiligo. I. Epidemiological profile in Calcutta, India. Genet Epidemiol. 1985; 2(1):71-8.

8. Akoglu G, Neselioglu S, Karaismailoglu E, Aktas A, Erel O. Plasma thiol levels are associated with disease severity in nonsegmental vitiligo. Indian J Dermatol 2018; 63:323-7.

9. Saran J, Dev N. Assessment of cases of vitiligo- A clinical study. J Adv Med Dent Scie Res. 2017; 5(1):169-171.

10. Ezzedine K, Sheth V, Rodrigues M, Eleftheriadou V, Harris JE, Hamzavi IH et al. Vitiligo is not a cosmetic disease. J Am Acad Dermatol. 2015; 73:883-5. 